\title{
Clinical comparison of patients with benign urachal masses versus urachal carcinomas
}

\author{
Xing $\mathrm{Bi}^{1+}$, Zhiming $\mathrm{Wu}^{2+}$, Hui Han ${ }^{2 *}$ and Fangjian Zhou ${ }^{2^{*}}$
}

\begin{abstract}
The clinical features of 17 patients with benign urachal masses and 30 patients with urachal carcinoma treated at Sun Yat-sen University Cancer Center were analyzed retrospectively. Univariate analysis indicated that seven parameters differed significantly between the two groups. Binary logistic regression analyses showed that the rate of gross hematuria was significantly higher $(P=0.042$, Exp $[B]=7.889)$ and the rate of fatty infiltration of the Retzius space was significantly lower $(P=0.006$, $\operatorname{Exp}[B]=0.028)$ in patients with urachal carcinoma than in those with benign urachal masses. Gross hematuria and fatty infiltration of the Retzius space may be indications of malignant and benign urachal masses, respectively.
\end{abstract}

Keywords: Urachal mass, Urachal carcinoma, Diagnosis

\section{Background}

Urachal masses may be malignant or benign, and the accuracy of preoperative diagnosis is poor [1-3]. In the present study, we retrospectively analyzed the clinical features of patients with both types of disease to identify indicators for accurate preoperative diagnosis to potentially prevent unnecessary resection.

\section{Patients and methods}

Clinical data of patients with urachal masses treated between 2000 and 2015 at Sun Yat-sen University Cancer Center were retrospectively analyzed. Patients were included if they (1) were aged $>18$ years, (2) had been diagnosed based on pathology, and (3) had lesions located in the dome or midline of the bladder. Additionally, patients with urachal carcinoma were included if (1) there was a sharp demarcation between the tumor and

\footnotetext{
*Correspondence: zhongshanhanhui@sina.com; zszhoufangjian@sina. com

${ }^{+}$Xing $\mathrm{Bi}$ and Zhiming Wu contributed equally to this work

${ }^{2}$ Department of Urology, State Key Laboratory of Oncology in South China, Collaborative Innovation Center for Cancer Medicine, Sun Yat-sen University Cancer Center, Guangzhou 510060, Guangdong, P. R. China Full list of author information is available at the end of the article
}

the bladder urothelium and (2) the patient did not have a primary adenocarcinoma of another organ [4].

All patients provided a detailed medical history. The parameters recorded included patient age, sex, the white blood cell count, the percentage of neutrophils, and the presence of gross hematuria, lower urinary tract symptoms (frequency, urgency, and dysuria), a palpable mass, lower abdominal pain (complaints of pain and tenderness), mucinuria, and calcification. Fatty infiltration of the Retzius space was characterized by enhanced patches or strips in the Retzius space, with vague indications of fat surrounding the lesion. Diffuse thickening of the adjacent bladder wall was characterized by thickening of the bladder wall not only around the lesions but also across the whole bladder dome and two side walls, with the peripheral wall gradually thinning to normal. Fatty infiltration and bladder wall thickening were examined using computed tomography (CT). All images were evaluated by two radiologists using the above criteria, with consistent results.

Continuous data were compared using independentsample $t$ test, and categorical data were compared using Chi square test. Factors differing significantly between patients with benign urachal masses and those with urachal carcinoma in the univariate analysis were further 
subjected to binary logistic regression analysis (likelihood ratio test). A $P$ value $<0.05$ was considered statistically significant.

\section{Results}

The study included 30 patients with urachal carcinoma (the malignant group) and 17 with benign urachal masses (the benign group). The baseline patient characteristics are shown in Table 1 . The median age was 45 years (range 22-62 years) in the malignant group and 41 years (range $18-75$ years) in the benign group $(P=0.362)$. The malignant group was composed of 21 (70\%) men and $9(30 \%)$ women, whereas the benign group was composed of 7 (41\%) men and 10 (59\%) women.

Of the 30 patients with urachal carcinoma, 29 had adenocarcinomas, and 1 had a sarcomatoid carcinoma combined with adenocarcinoma. Of the 17 patients with benign urachal masses, 15 had infected urachal cysts with chronic inflammation, and 2 had xanthogranuloma. Imaging indices are presented in Fig. 1.

Table 1 shows the univariate analysis of all 12 parameters compared between the malignant and benign groups. No significant differences were observed in age, sex, the presence of a palpable mass, mucinuria, or calcification. The rate of gross hematuria was higher in the malignant group than in the benign group $(P=0.021)$. In contrast, the rates of lower urinary tract symptoms $(P=0.011)$, lower abdominal pain $(P=0.004)$, fatty infiltration of the Retzius space $(P<0.001)$, and diffuse thickening of the adjacent bladder wall $(P<0.001)$ as well as the percentage of neutrophils $(P=0.004)$ and the white blood cell count $(P=0.001)$ were significantly higher in the benign group than in the malignant group.

Binary logistic regression analysis of the seven parameters that differed significantly between the two groups in the univariate analysis showed that the rate of gross hematuria was significantly higher $(P=0.042$, $\operatorname{Exp}[\mathrm{B}]=7.889)$ and the rate of fatty infiltration of the Retzius space was significantly lower $(P=0.006$, $\operatorname{Exp}[\mathrm{B}]=0.028)$ in the malignant group than in the benign group.

\section{Discussion}

Urachal carcinoma is a rare but highly malignant epithelial cancer that is difficult to distinguish from a benign urachal mass [5]. Urachal inflammation and certain benign urachal neoplasms, including adenomas, fibromas, villous adenomas, and mucinous cystadenomas, can form masses.

Urachal carcinoma has been reported more frequently in men than in women (1.49:1), and most patients are older than 50 years [6, 7]. However, in the present study, the median age of the patients with urachal carcinoma
Table 1 Univariate analysis of all 12 parameters compared between patients with benign urachal masses and those with urachal carcinoma

\begin{tabular}{|c|c|c|c|}
\hline Variable & $\begin{array}{l}\text { Benign urachal } \\
\text { masses (cases) }\end{array}$ & $\begin{array}{l}\text { Urachal carci- } \\
\text { noma (cases) }\end{array}$ & $P$ value \\
\hline Total & 17 & 30 & \\
\hline Sex & & & 0.053 \\
\hline Male & 7 & 21 & \\
\hline Female & 10 & 9 & \\
\hline Gross hematuria & & & 0.021 \\
\hline Present & 6 & 21 & \\
\hline Absent & 11 & 9 & \\
\hline $\begin{array}{l}\text { Lower urinary tract } \\
\text { symptoms }\end{array}$ & & & 0.011 \\
\hline Present & 8 & 4 & \\
\hline Absent & 9 & 26 & \\
\hline Palpable mass & & & 0.632 \\
\hline Present & 1 & 3 & \\
\hline Absent & 16 & 27 & \\
\hline $\begin{array}{l}\text { Lower abdominal } \\
\text { pain }\end{array}$ & & & 0.004 \\
\hline Present & 8 & 3 & \\
\hline Absent & 9 & 27 & \\
\hline Mucinuria & & & 0.283 \\
\hline Present & 0 & 2 & \\
\hline Absent & 17 & 28 & \\
\hline $\begin{array}{l}\text { White blood cell } \\
\text { count }\end{array}$ & & & 0.001 \\
\hline$\geq 10 \times 10^{9} / \mathrm{L}$ & 7 & 0 & \\
\hline$<10 \times 10^{9} / \mathrm{L}$ & 10 & 30 & \\
\hline $\begin{array}{l}\text { Percentage of } \\
\text { neutrophils (\%) }\end{array}$ & & & 0.004 \\
\hline$\geq 70$ & 9 & 3 & \\
\hline$<70$ & 8 & 27 & \\
\hline Calcification & & & 0.449 \\
\hline Present & 6 & 14 & \\
\hline Absent & 11 & 16 & \\
\hline $\begin{array}{l}\text { Fatty infiltration of } \\
\text { the Retzius space }\end{array}$ & & & $<0.001$ \\
\hline Present & 12 & 1 & \\
\hline Absent & 5 & 29 & \\
\hline $\begin{array}{l}\text { Diffuse thickening } \\
\text { of adjacent blad- } \\
\text { der wall }\end{array}$ & & & $<0.001$ \\
\hline Present & 9 & 0 & \\
\hline Absent & 8 & 30 & \\
\hline
\end{tabular}

was 45 years, with no significant differences between the two groups in terms of age or sex.

Multivariate analysis identified two parameters that differed significantly between the benign and the malignant groups. Gross hematuria was significantly associated with urachal carcinoma $(P=0.042)$, 

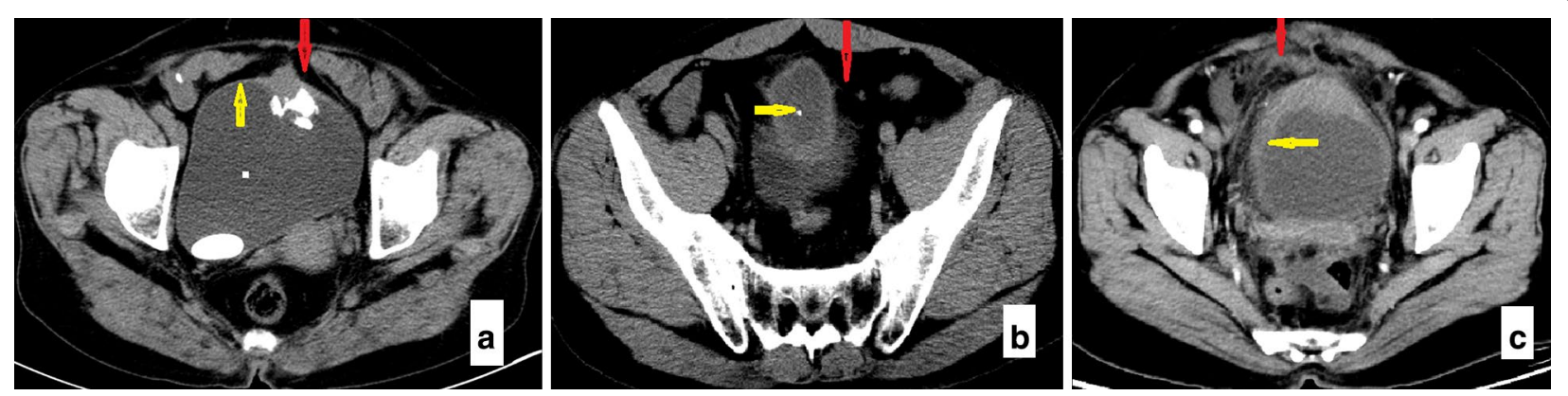

Fig. 1 Computed tomography (CT) manifestations of a urachal carcinoma and a benign urachal mass. a On an axial view of a urachal carcinoma, the red arrow indicates the Retzius space without fat infiltration, and the yellow arrow indicates a lack of thickening of the surrounding bladder wall. b On an axial view of a urachal carcinoma, the red arrow indicates the Retzius space without fat infiltration, and the yellow arrow indicates calcification in central lesions. c On an axial view of a benign urachal mass, the red arrow indicates fatty infiltration of the Retzius space, characterized by enhancements of some patches or strips and vague indications of fat surrounding the lesions, and the yellow arrow indicates diffuse thickening of the bladder wall not only around the lesions but also across the whole bladder dome and two side walls, with the peripheral wall gradually thinning to normal

whereas fatty infiltration of the Retzius space was significantly associated with benign urachal masses $(P=0.006)$. These results were consistent with those of previous reports, in which hematuria was a common risk factor for malignancy $[8,9]$. Fatty infiltration of the Retzius space has also been reported to be an important indirect sign of inflammation in patients with urachal cysts [10].

This study had several limitations, including its retrospective nature and the small number of patients. In addition, all of the benign urachal masses were inflamed. Thus, these results may not apply to all types of benign neoplasms.

\section{Conclusions}

This study showed that gross hematuria was significantly associated with urachal carcinoma, whereas fatty infiltration of the Retzius space was significantly associated with benign urachal masses. Additional studies are needed to verify these findings.

\section{Authors' contributions}

FJZ and $\mathrm{HH}$ conceived of the study and participated in its design and coordination. XB and ZMW performed the statistical analyses and drafted the manuscript. All authors read and approved the final manuscript.

\section{Author details}

${ }^{1}$ Department of Urology, Tumor Hospital affiliated with the Xinjiang Medical University, Urumqi 830011, Xinjiang, P. R. China. ${ }^{2}$ Department of Urology, State Key Laboratory of Oncology in South China, Collaborative Innovation Center for Cancer Medicine, Sun Yat-sen University Cancer Center, Guangzhou 510060, Guangdong, P. R. China.

\section{Acknowledgements}

The authors acknowledge Jing Han and Jian Zhou for their assistance in evaluation of the images.

\section{Competing interests}

The authors declare that they have no competing interests.

Received: 22 February 2016 Accepted: 20 July 2016

Published online: 07 January 2017

\section{References}

1. Meeks JJ, Herr HW, Bernstein M, Al-Ahmadie HA, Dalbagni G. Preoperative accuracy of diagnostic evaluation of the urachal mass. J Urol. 2013;189(4):1260-2.

2. Cooper UL, Sopko NA, Bivalacqua TJ. Evaluation and treatment of an unusual urachal mass: a case report. Springer Plus. 2015;4(1):1-4.

3. Allen JW, Song J, Velcek FT. Acute presentation of infected urachal cysts case report and review of diagnosis and therapeutic interventions. Pediatr Emerg Care. 2004;20(2):108-11.

4. Johnson DE, Hodge GB, Abdul-Karim FW, Ayala AG. Urochal carcinoma. Urology. 1985;26:218-21.

5. Pal DK, Chowdhury MK. Urachal adenocarcinoma masquerading as an urachal cyst. Indian J Surg. 2008;70(3):135-7.

6. Zhang J, Wu J. Options for diagnosis and treatment of urachal carcinoma. Asia Pac J Clin Oncol. 2013;9:117-22.

7. Henly DR, Farrow GM, Zincke H. Urachal cancer: role of conservative surgery. Urology. 1993;42(6):635-9.

8. Ashley RA, Inman BA, Routh JC, Rohlinger AL, Husmann DA, Kramer SA. Urachal anomalies: a longitudinal study of urachal remnants in children and adults. J Urol. 2007;178(4, Supplement):1615-8.

9. Ashley RA, Inman BA, Sebo TJ, Leibovich BC, Blute ML, Kwon ED, et al. Urachal carcinoma: clinicopathologic features and long-term outcomes of an aggressive malignancy. Cancer. 2006;107(4):712-20.

10. Jin $\mathrm{XL}$, Yang HF, Yong DU. Diagnostic value of $\mathrm{CT}$ in urachal cyst. Radiol Pract. 2009;24(8):878-81 (In Chinese) 